Check for updates

Cite this: RSC Adv., 2019, 9, 6102

Received 25th December 2018

Accepted 31st January 2019

DOI: $10.1039 / \mathrm{c} 8 \mathrm{ra10544h}$

rsc.li/rsc-advances

\section{Well-confined polyoxometalate-ionic liquid in silicic framework for environmentally friendly asymmetric di-hydroxylation of olefins $\uparrow$}

\author{
Dong Liang, (D) $\ddagger^{\mathrm{a}}$ Yan Wang, (D) $\ddagger^{\mathrm{b}}$ Sifan Wang, ${ }^{\mathrm{a}}$ Chengkun Song, ${ }^{\mathrm{c}}$ Yonghe Shi, ${ }^{\mathrm{a}}$ \\ Qinghao Liu, (iD a Hailin Zhu, ${ }^{a}$ Xia Li, (D) a Laishuan Liu*a and Na Zhu*d
}

Chiral 1,2-diols with a high yield could be directly prepared from asymmetric di-hydroxylation of olefins via an eco-friendly and enduring catalyst, in which abundant "chiral pools" of polyoxometalate-ionic liquid were target-designed into the silicic framework (POM-ILS) and well stabilized in aqueous media.

\section{Introduction}

Optically active 1,2-diols can provide substrates and intermediates for chiral drugs, pesticides and cosmetics. Previously, they were often synthesized via asymmetric hydrolysis of epoxides and di-hydroxylation of olefins. ${ }^{1}$ In particular, for the latter transformation, progressive data have been attained for osmium catalysts; however, they are still not close to the industrial applications owing to the high toxicity, volatility and secondary contamination of osmium species. ${ }^{2} \mathrm{~A}$ few researchers have proposed a greener alternative route, in which modified polyoxometalates (POMs) with chiral ligands or ionic liquids can present desirable enantioselectivity for di-hydroxylation. ${ }^{3}$ The complex stereo-catalytic systems can also be smoothly applied in the asymmetric cross-aldol reaction, Mannich reaction, Michael addition, Diels-Alder cycloaddition, etc. ${ }^{4}$

Nevertheless, it must be pointed out that the high solubilities of organic ligands, ionic liquids and polyoxometalates in water and solvents make them unstable for use. To address this issue, considerable efforts have been devoted to stabilizing these complex "chiral pools". The first and most popular attempt is screening different types of polymeric and inorganic carriers, pre-anchoring the organic groups on surfaces or encapsulating them into frameworks, and then combining them with polyoxometalates. ${ }^{5}$ As proved by some concrete examples, particularly oxidation and esterification, the stability

${ }^{a}$ School of Chemical Engineering and Technology, North University of China, Taiyuan, People's Republic of China, 030051. E-mail: Liulaishuan@nuc.edu.cn

${ }^{b}$ College of Chemistry and Chemical Engineering, Taiyuan University of Technology, Taiyuan, People's Republic of China, 030024

'School of Chemistry and Chemical Engineering, Southeast University, Nanjing, People's Republic of China, 211189

${ }^{d}$ College of Environment and Resource, Shanxi University, Taiyuan, People's Republic of China, 030006. E-mail: zhuna@sxu.edu.cn

$\dagger$ Electronic supplementary information (ESI) available. See DOI: $10.1039 / \mathrm{c} 8 \mathrm{ra} 10544 \mathrm{~h}$

\$ The first two authors contributed equally to this paper. of complex catalysts remains at a satisfactory level even after several recycles. ${ }^{6}$

Another route involves the current in situ technologies such as metal-organic frameworks (MOFs), periodic mesoporous organosilica (PMO) and polymerizable ionic liquids (PILs), ${ }^{7}$ which indicate that functional catalytic precursors can develop with the growth of the skeleton; thus, their catalytic capacity can be deeply promoted by the surrounding environment. Also, with more content of POMs and paired organics, their catalytic capacity and efficiency will be much better. Inspired by the above-mentioned works, we developed a simple in situ process to obtain toughness of hybrids in aqueous media.

\section{Experimental}

\subsection{Preparation of catalysts}

Inspired by the above works, we developed a simple in situ process to obtain toughness of hybrids in aqueous media. In brief, darkyellow chiral ionic-liquid silicone (ILS) was first pre-synthesized with a substitution reaction between 3-chloropropyltriethoxysilane and transparent $S$-nicotine at equimolar amount under reflux in methanol for $24 \mathrm{~h}$. This natural alkaloid is one of important by-products of the tobacco industry and it may be evolved into a chiral solvent or catalyst. ${ }^{8}$ Then, certain amounts of 12-tungstophosphoric acid (TPA) and $75 \% \mathrm{H}_{3} \mathrm{PO}_{4}$ were dissolved in methanol, incorporated into the above IL solution and cultured for another $24 \mathrm{~h}$ till the formation of a tough framework. The molar ratios of 12-TPA, ILS, $\mathrm{H}_{3} \mathrm{PO}_{4}$ and methanol were separately controlled as $1: 1: 1: 100,1: 2: 1: 100$, and $1: 3: 1: 100$. The final pink precipitates were centrifuged, washed, dried and denoted as POM-ILS (1/1), POM-ILS (1/2), and POM-ILS (1/3).

Non-silica POM-IL and non-IL POM-S catalysts were required as contrasts to prove the reaction mechanism. For the former, transparent $S$-nicotine was directly precipitated with TPA anions. The yellow solid was produced and named as a POM-IL catalyst. For the latter, 3-aminopropyl-triethoxysilane was used in place of the above CIL solution for precipitation with TPA. 
The white solid was produced and denoted as the POM-S catalyst.

\subsection{Characterization of catalysts}

FTIR spectra were recorded on a Fourier transform infrared spectrometer (Nicolet Nexus 470) using the conventional $\mathrm{KBr}$ pellet method. Thermogravimetric (TG) analysis was conducted on a Mettler Toledo TGA/SDTA851 analyzer (Switzerland) from $80{ }^{\circ} \mathrm{C}$ to $800{ }^{\circ} \mathrm{C}\left(10{ }^{\circ} \mathrm{C} \mathrm{min}{ }^{-1}\right)$ under nitrogen $\left(20 \mathrm{~mL} \mathrm{~min}{ }^{-1}\right)$. The BET surface area of the catalyst was measured using nitrogen adsorption at $-196^{\circ} \mathrm{C}$ with a Quantachrome Autosorb analyzer. SEM was performed using a Philips FEI Quanta 200 instrument equipped with EDX capability.

\subsection{Di-hydroxylation of olefins}

The above five catalysts were all applied for di-hydroxylation of styrene. In every attempt, $50 \mathrm{mg}$ catalyst, $100 \mu \mathrm{L}$ styrene and 150 $\mu \mathrm{L} 30 \% \mathrm{H}_{2} \mathrm{O}_{2}$ were added into $10 \mathrm{~mL} \mathrm{H}_{2} \mathrm{O}$ at $55-60{ }^{\circ} \mathrm{C}$ for $2.5 \mathrm{~h}$. After completion of the reaction, the catalyst was recycled by centrifugation, washed with EtOH $(3 \times 5 \mathrm{~mL})$ and dried in vacuum. Excess $\mathrm{H}_{2} \mathrm{O}_{2}$ was eliminated using $\mathrm{MnO}_{2}$. The final liquid was extracted with $\mathrm{CH}_{2} \mathrm{Cl}_{2}(3 \times 5 \mathrm{~mL})$ and the extract was concentrated to $1 \mathrm{~mL}$. Quantitative analysis of the products was performed with Agilent-6890N GC using a capillary column (HP$5,30 \mathrm{~m} \times 0.25 \mathrm{~mm} \times 0.53 \mu \mathrm{m})$ with an FID detector. Optical products were identified by Agilent-1200 HPLC using a chiral column (Chiralcel OB-H) and eluted with hexane/isopropanol = $8: 2(\mathrm{v} / \mathrm{v})$ at a flow rate of $0.5 \mathrm{~mL} \mathrm{~min}^{-1}$, with retention times of
$13.5 \mathrm{~min}$ for $S$-1-phenyl-2-ethanediol and $16.7 \mathrm{~min}$ for $R$-1phenyl-2-ethanediol.

Di-hydroxylation of cyclohexene is another prototypical reaction. POM-ILS (1/3) was preferred for examining the endurance and applicability of catalysts. In every attempt, $50 \mathrm{mg}$ of catalyst, $100 \mu \mathrm{L}$ of cyclohexene and $150 \mu \mathrm{L}$ of $30 \% \mathrm{H}_{2} \mathrm{O}_{2}$ were added into $10 \mathrm{~mL}$ of $\mathrm{H}_{2} \mathrm{O}$ at $55-60{ }^{\circ} \mathrm{C}$ for $2.5 \mathrm{~h}$. After the reaction, the catalyst was centrifuged, washed and dried in vacuum for subsequent use. The final products were extracted and analyzed by GC. The optical products were identified by HPLC and were eluted with hexane/isopropanol $=8: 2(\mathrm{v} / \mathrm{v})$ at a flow rate of $0.5 \mathrm{~mL} \mathrm{~min}^{-1}$, with retention times of $7.4 \mathrm{~min}$ for cis-1,2cyclohexanediol and $8.1 \mathrm{~min}$ for trans-1,2-cyclohexanediol.

\section{Results and discussion}

The characteristic composition and properties of the studied materials are presented in Fig. 1. The FT-IR spectrum shows the parent peaks of polyoxymetalates and organic ionic liquids. IR $\left(\mathrm{KBr}\right.$ disc, $\left.\mathrm{cm}^{-1}\right)$ : 3540, 3064, 2970, 2891, 2700, $\nu(\mathrm{N}-\mathrm{H}, \mathrm{C}-\mathrm{H})$; 1638, 1566, 1508, 1460, $\nu(\mathrm{C}=\mathrm{C}, \mathrm{C}=\mathrm{N}) ; 1078,980,893,802,520$, $\nu(\mathrm{P}-\mathrm{O}, \mathrm{W}-\mathrm{O}, \mathrm{W}-\mathrm{O}-\mathrm{W}, \mathrm{W}-\mathrm{O}-\mathrm{O}) .{ }^{9}$ The BET surface area was 68 $\mathrm{cm}^{3} \mathrm{~g}^{-1}$ and the average pore diameter was $1.85 \mathrm{~nm}$. The TG analysis revealed the composition of volatile components. A significant weight loss of $11.7 \%$ was observed in the range of 400-600 ${ }^{\circ} \mathrm{C}$ due to the organic content and after that, $4.4 \%$ weight loss was observed, which could be attributed to $\mathrm{PO}_{x}$ in POM. As shown in SEM images, the POM-ILS (1/3) nanoparticles
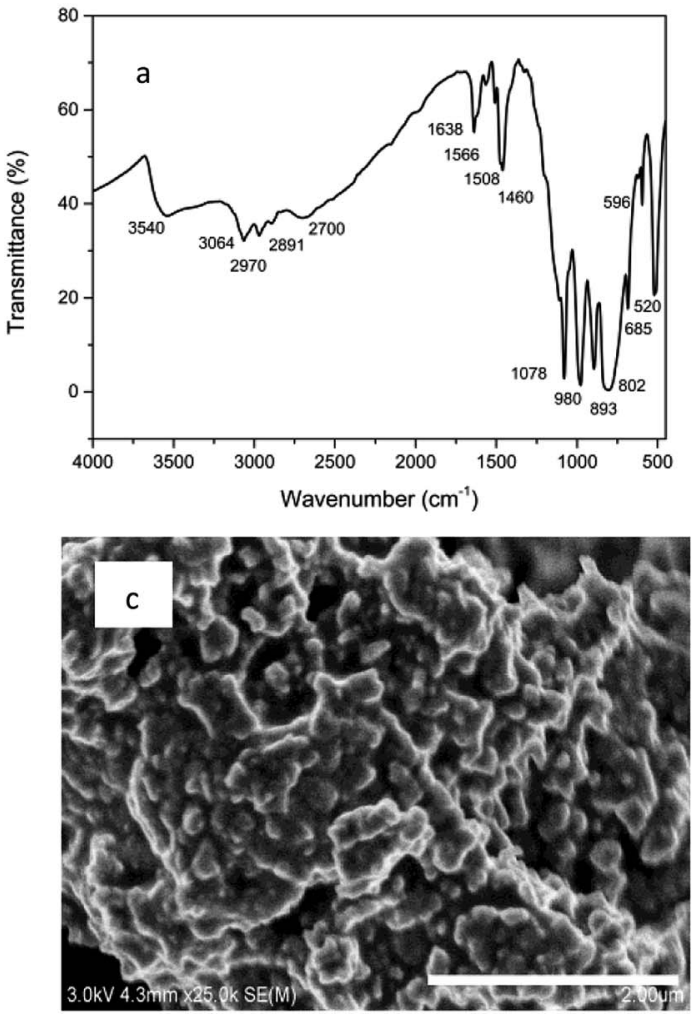
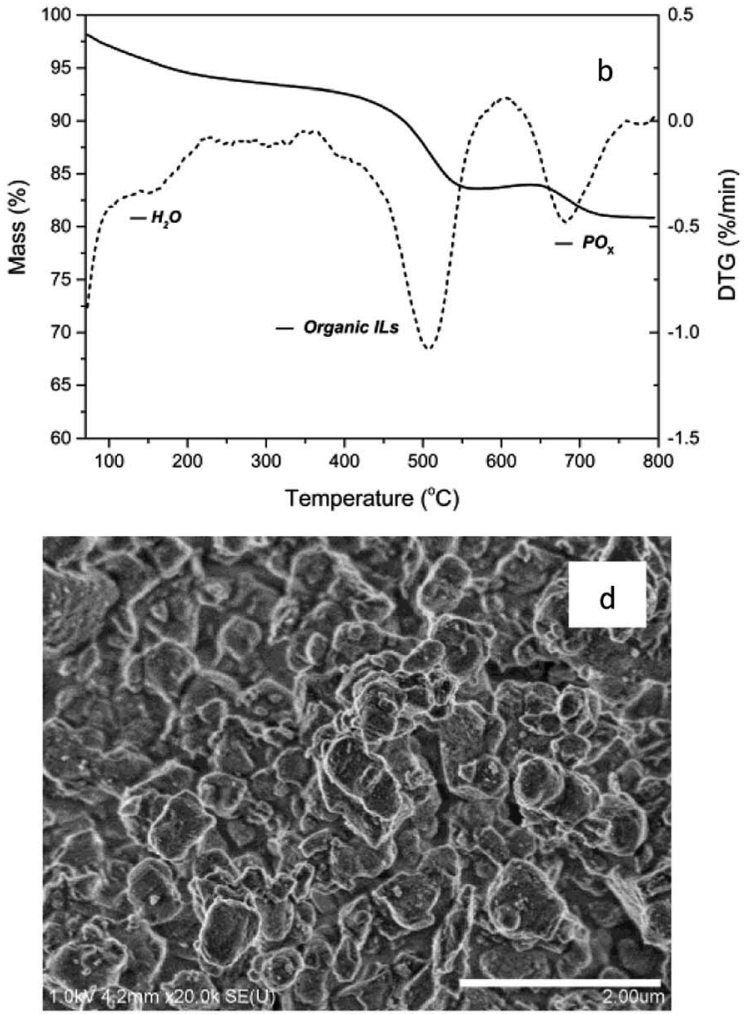

Fig. 1 FTIR, TG, SEM of POM-ILS(3/1) ( $a, b$ and $c$ ) and SEM of POM (d). 
displayed relatively narrow size distribution with diameter of 180-220 $\mathrm{nm}$. The amount of tungsten loaded was $2.54 \mathrm{mmol}$ $\mathrm{g}^{-1}$, which was calculated from the EDX spectrum.

The collaborative confinement of POM anions by ionic liquids and silicic frameworks is considered to be mainly responsible for the stability of complex catalysts. To prove this, the ratios of POM anions to ILS in structure were controlled to $1 /$ 2 and 1/1, corresponding to POM-ILS (1/2) and POM-ILS (1/1). Then, the dissolution of TPA into water was examined using a UV spectrophotometer at a wavelength of $253 \mathrm{~nm}$. The data in Fig. 2 show that the stability of the catalyst gradually declined with the reduction in ionic liquid content. We found $5.4 \%$, $19.6 \%$ and $33.8 \%$ TPA in three catalysts, which separately leached into water after being treated for $3 \mathrm{~h}$ at $55-60{ }^{\circ} \mathrm{C}$. Moreover, nearly $40 \%$ of TPA in POM-IL dissolved in water after $3 \mathrm{~h}$ without protection of the silicic framework. After replacing 3-aminopropyltriethoxysilane with the above-mentioned ionicliquid silicone, the catalyst was prepared and named as POM$\mathrm{S}$, in which the majority of TPA could not be stably reserved in the final structure.

Initially, di-hydroxylation of styrene was selected as a prototypical reaction to examine the catalytic activity in neat water. The results are summarized in Table 1 . It was found that the complex catalyst was efficient for the asymmetric transformation of styrene with $\mathrm{H}_{2} \mathrm{O}_{2}$. In contrast, the control POM-S without ionic liquids yielded a small quantity of racemic diols (Table 1, entry 1). The conversion of styrene increased with the employment of ionic liquids and optically active products were achieved on POM-IL (Table 1, entry 2). POM-IL without silicic components may be considered as a "pseudo" homogeneous

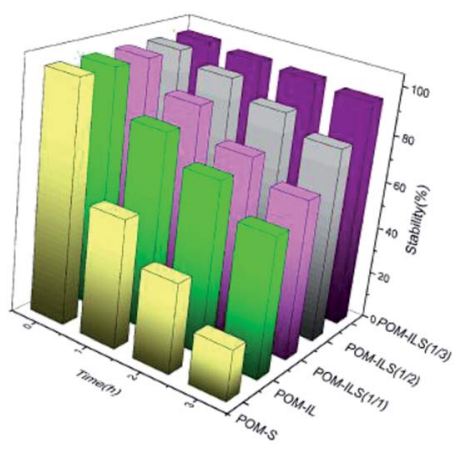

Fig. 2 TPA stability of catalysts in hot water.

Table 1 Catalytic performance on asymmetric di-hydroxylation of styrene $^{a}$

\begin{tabular}{lllll}
\hline Catalysts & Conv.\% & Sel. $\%_{\mathrm{BA}}$ & Sel. $\%_{\text {diols }}$ & e.e.\% $(R / S)$ \\
\hline POM-S & 58 & 41 & 59 & 0 \\
POM-IL & 99 & 55 & 45 & 78 \\
POM-ILS(1/1) & 77 & 43 & 57 & 82 \\
POM-ILS(1/2) & 83 & 18 & 82 & 87 \\
POM-ILS $(1 / 3)$ & 96 & 10 & 90 & 95 \\
POM-ILS $(1 / 3)_{7}$ & 86 & 12 & 88 & 94
\end{tabular}

${ }^{a}$ Benzaldehyde (BA) is the main by-product. catalyst because it can be dissolved into a hot $\mathrm{H}_{2} \mathrm{O}_{2}$ solution and precipitated until the medium is cooled and the oxidants run off. ${ }^{10}$ Also, the catalyst could realize higher efficiency than heterogeneous catalysts, but the 1,2-diols were not the dominant products. When the POM anions were surrounded with abundant chiral ionic liquids, the selectivity of vicinal diols remarkably increased from $57 \%$ to $90 \%$ and the enantiomeric excess of $R / S$ isomers remained at a satisfactory level of $82-95 \%$ (Table 1, entries 3-5). After seven recycles, POM-ILS (1/3) still exhibited better activity than other catalysts and slight decrease could be observed (Table 1, entry 6).

The difference in their catalytic properties might be further understood via characterization of ${ }^{29}$ Si MAS NMR and ${ }^{31} \mathrm{P}$ MAS NMR. Fig. 3a shows the observed resonances in ${ }^{29} \mathrm{Si}$ NMR spectra. T2 $(-57 \mathrm{ppm})$ and $\mathrm{T} 3(-64 \mathrm{ppm})$ represented the $\mathrm{Si}$ atom environments of $-\mathrm{CH}_{2}-\mathrm{Si}(\mathrm{OR})(\mathrm{OSi})_{2}$ and $-\mathrm{CH}_{2}-\mathrm{Si}(\mathrm{OSi})_{3}$, respectively. ${ }^{11}$ In addition to the increase in ionic liquidsilicone, silicate thoroughly condensed and the percentage content of T3 peak in total peaks was found to be slightly higher than that of T2 peak. Fig. 3b presents the chemical resonances in ${ }^{31} \mathrm{P}$ NMR spectra. The peaks (from $-14 \mathrm{ppm}$ to $-16 \mathrm{ppm}$ ) could be attributed to 12-phosphotungstic acid. ${ }^{\mathbf{1 2}}$ There was also a negligible shift of 1-2 ppm probably because of the electrostatic impacts of acidic-basic principles. These results suggested that the ionic liquid-based silicic framework was realized as expected, and the catalytic capacity of POMs was improved by the neighbouring chiral ligands.

Furthermore, another example was carried out to explore the scope of our protocol for asymmetric di-hydroxylation. Cyclohexene was employed under similar conditions using the POMILS (1/3) and $\mathrm{H}_{2} \mathrm{O}_{2}$ system. The reusability of catalyst was then established with the preferred catalysts after each run (Table 2). After the first use, the catalyst was separated, washed, dried and subjected to another fresh cycle. Seven consecutive preparation processes of trans/cis-1,2-cyclohexanediol showed no significant loss in yield, indicating that the activity of recovered catalysts
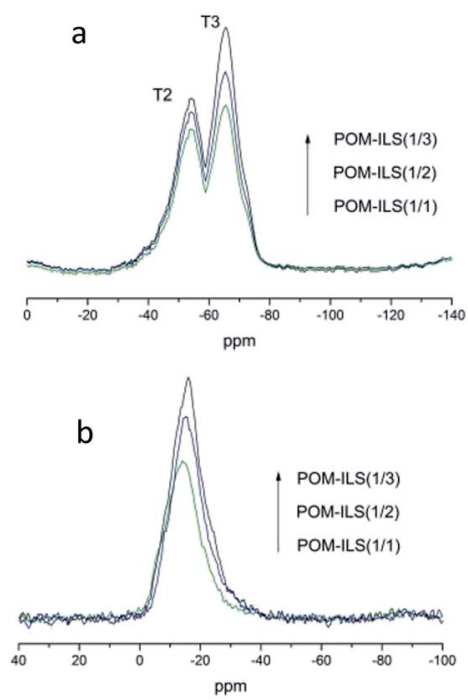

Fig. $3{ }^{29} \mathrm{Si}-\mathrm{NMR}(\mathrm{a})$ and ${ }^{31} \mathrm{P}-\mathrm{NMR}(\mathrm{b})$ of POM-ILS catalysts. 
Table 2 Recycling experiments for asymmetric di-hydroxylation of cyclohexene $^{a}$

\begin{tabular}{llllllll}
\hline Cycles & 1 & 2 & 3 & 4 & 5 & 6 & 7 \\
Conv.\% & 96 & 95 & 96 & 94 & 95 & 93 & 93 \\
Sel. $\%_{\text {diols }}$ & 92 & 92 & 90 & 91 & 90 & 89 & 89 \\
e.e. $\%_{\text {(trans/cis })}$ & 93 & 95 & 92 & 94 & 91 & 92 & 90 \\
$W_{\left(\text {mmol g }^{-1}\right)}$ & 2.53 & 2.53 & 2.51 & 2.48 & 2.45 & 2.44 & 2.42
\end{tabular}

${ }^{a}$ Only a small amount of cyclohexanone was formed.



Fig. 4 Schematic of double-locked POM catalysts by silicic frameworks and chiral ionic liquids.

did not change significantly compared with that of the fresh catalyst. Also, no significant loss in stereo-selectivity was observed and the trans-products were always the dominant products.

Undoubtedly, enantiomerically pure alkaloids such as nicotine, cinchonidine, quinidine and ephedrine as well as various amino acids can be utilized as origins of chiral ionic liquids and can provide a favorable and soft pool for asymmetric transformations. ${ }^{13}$ Now, the dark phosphotungstic anions can be engaged to immobilize blue chiral ILs (Fig. 4); this is similar to how they rapidly freeze vulnerable cells and micelles in experiments related to biochemistry and colloid polymer science. Meanwhile, the yellow organic silicates grafted on ionic liquids undergo polycondensation under acidic conditions and afford toughness of the hybrid structure.

\section{Conclusions}

In summary, polyoxometalate anions might be double-locked with the silicic framework and ionic liquid, which profoundly confirmed that the heterogenous catalysts could survive in hot $\mathrm{H}_{2} \mathrm{O}_{2}$ solution. Apart from this, catalytic POM-IL hybrids were introduced from the starting step and presented a richer content than any other previous material (Table S1†). ${ }^{14}$ The in situ-planted abundant "chiral pools" might be responsible for the exceptional activity and enantioselectivity of the catalyst in this study.

\section{Conflicts of interest}

The authors declare that there is no conflict of interests regarding the publication of this full article.

\section{Acknowledgements}

Thanks for the financial supports by the National Natural Science Foundation of China (No. 21406211, 21407101, 21605133, 51701188) and the Natural Science Foundation of Shanxi Province (No. 201701D221040, 201701D221196).

\section{Notes and references}

1 A. Duarah, A. Goswami, T. C. Bora, et al., Appl. Biochem. Biotechnol., 2013, 170, 1965; Y. C. He, C. L. Ma, X. Zhang, et al., Appl. Biochem. Biotechnol., 2013, 97, 7185; S. Kobayashi and M. Sugiura, Adv. Synth. Catal., 2006, 348, 1496.

2 L. C. Branco and C. A. M. Afonso, J. Org. Chem., 2004, 69, 4381; S. M. Reddy, M. Srinivasulu, Y. V. Reddy, et al., Tetrahedron Lett., 2006, 47, 5285; D. Choi, S. Han, E. Kwueon, et al., Adv. Synth. Catal., 2006, 348, 2560; B. Balagam, R. Mitra and D. E. Richardson, Tetrahedron Lett., 2008, 49, 1071; R. Akiyama, N. Matsuki, H. Nomura, et al., RSC Adv., 2012, 2, 7456.

3 D. Y. Du, L. K. Yan, Z. M. Su, et al., Coord. Chem. Rev., 2013, 257, 702; D. Liang, N. Zhu, H. L. Zhu, et al., Catal. Commun., 2016, 79, 49.

4 S. Z. Luo, J. Y. Li, H. Xu, et al., Org. Lett., 2007, 9, 3675; Q. Gao, S. M. Lu, Y. Liu, et al., Tetrahedron Lett., 2011, 52, 3779; Q. Gao, Y. Liu, S. M. Lu, et al., Green Chem., 2011, 13, 1983; Q. Chen, C. Xin, L. L. Lou, et al., J. Inorg. Organomet. Polym., 2013, 23, 467.

5 L. T. A. Sofia, A. Krishnan, M. Sankar, et al., J. Phys. Chem. C, 2009, 113, 21114; R. Hajian, S. Tangestaninejad, M. Moghadam, et al., J. Coord. Chem., 2011, 64, 4134; J. Zhu, P. Wang and M. Lu, RSC Adv., 2012, 2, 8265; M. Li, M. Zhang, A. Wei, et al., J. Mol. Catal. A: Chem., 2015, 406, 23; M. Zhang, M. Li, Q. Chen, et al., RSC Adv., 2015, 5, 76048; Y. Mei and B. Yan, Colloid Polym. Sci., 2015, 293, 817; S. Herrmann, L. De Matteis, J. M. De La Fuente, et al., Angew. Chem., Int. Ed., 2017, 56, 1667.

6 K. Yamaguchi, C. Yoshida, S. Uchida, et al., J. Am. Chem. Soc., 2005, 127, 530; J. Kasai, Y. Nakagawa, S. Uchida, et al., Chem.-Eur. J., 2006, 12, 4176; A. Bordoloi, S. Suman, F. Lefebvre, et al., J. Catal., 2008, 259, 232; S. Doherty, J. G. Knight, J. R. Ellison, et al., Green Chem., 2012, 14, 925; R. Hajian, S. Tangestaninejad, M. Moghadam, et al., C. R. Chim., 2012, 15, 975; R. Tan, C. Liu, N. Feng, et al., Microporous Mesoporous Mater., 2012, 158, 77; H. Zhao, L. Zeng, Y. Li, et al., Microporous Mesoporous Mater., 2013, 172, 67; L. Hua, J. Chen, C. Chen, et al., New J. Chem., 2014, 38, 3953; Y. Leng, J. Wu, P. Jiang, et al., Catal. Sci. Technol., 2014, 4, 1293; S. Xun, D. Zheng, S. Yin, et al., RSC Adv., 2016, 6, 42402; W. Jiang, D. Zheng, S. Xun, et al., Fuel, 2017, 190, 1.

7 M. A. Neouze, J. L. Bideau, P. Gaveau, et al., Chem. Mater., 2006, 18, 3931; R. N. Biboum, F. Doungmene, B. Keita, et al., J. Mater. Chem., 2011, 22, 319; Y. Leng, J. Liu, P. Jiang, et al., RSC Adv., 2012, 2, 11653; J. Yuan, D. Mecerreyes and M. Antonietti, Prog. Polym. Sci., 2013, 
38, 1009; M. H. Yang, B. G. Choi, S. C. Jung, et al., Adv. Funct. Mater., 2015, 24, 7301.

8 T. Kitazume, US Pat., US 20010031875A1, 2001; T. Heckel, A. Winkel and R. Wilhelm, Tetrahedron: Asymmetry, 2013, 24, 1127; A. R. Hajipour, Y. Heidari and G. Kozehgary, RSC Adv., 2015, 5, 61179.

9 S. Bareyt, S. Piligkos, B. Hasenknopf, et al., J. Am. Chem. Soc., 2005, 127, 6788; P. M. Rao, A. Wolfson, S. Kababya, et al., J. Catal., 2005, 232, 210; L. N. Yang, Y. T. Qi, X. D. Yuan, et al., J. Mol. Catal. A: Chem., 2005, 229, 199.

10 N. Mizuno and K. Yamaguchi, Chem. Rec., 2010, 6, 12; S. Ivanova, ChemInform, 2016, 47, 240.

11 V. Lahootun, C. Besson, R. Villanneau, et al., J. Am. Chem. Soc., 2007, 129, 7127; H. Chen, W. L. Dai, X. L. Yang, et al.,
Appl. Catal., A, 2006, 309, 62; S. Zhang, et al., J. Mol. Catal. A: Chem., 2008, 289, 22.

12 E. Lindner, A. Baumann, P. Wegner, et al., J. Mater. Chem., 2000, 10, 1655; X. Zhang, D. Wang, N. Zhao, et al., Catal. Commun., 2009, 11, 43.

13 C. Baudequin, J. Baudoux, J. Levillain, et al., Tetrahedron: Asymmetry, 2003, 14, 3081; H. Ohno and K. Fukumoto, Acc. Chem. Res., 2007, 40, 1122; J. Ding and D. W. Armstrong, Chirality, 2010, 17, 281; M. Vasiloiu and K. Bica. Chiral Ionic Liquids in Separation Sciences. 2016.

14 A. Mandoli, D. Pini, M. Fiori, et al., Eur. J. Org. Chem., 2005, 7, 1271; D. S. Choi, S. S. Han, E. K. Kwueon, et al., Adv. Synth. Catal., 2010, 348, 2560; L. C. Branco, A. Serbanovic, N. D. P. Manuel, et al., ACS Catal., 2011, 1, 1408. 